\title{
ABOUT THE DYNAMIC BEHAVIOUR OF COMPOSITE BARS REINFORCED WITH COTTON OR HEMP FIBERS
}

\author{
A. I. Radoi1, C. M. Miritoiu1* \\ ${ }^{1}$ University of Craiova, Faculty of Mechanics, Romania \\ *Corresponding author's e-mail address: miritoiucosmin@yahoo.com
}

\begin{abstract}
This paper presents several designed green composites with natural reinforcements (hemp and cotton fibers), the matrix being a synthetic resin (epoxy resin). In order to characterise the dynamic behaviour of materials, bars free vibrations were used to determine the dynamic parameters. The bars were clamped at one end and left free at the other end. At the free end, a Bruel\&Kjaer accelerometer with $0.04 \mathrm{pC} / \mathrm{ms}^{-2}$ sensitivity was placed, in order to record the beam dynamic response. A force was applied at the free end to bend the beams, and after bending, the force was cancelled and the beams were left to vibrate freely. The accelerometer was connected to a Nexus signal conditioner, and the signal conditioner was connected to a SPIDER 8 data acquisition system made by Hottinger Baldwin Messtec. The acquisition system was connected to a notebook and the experimental parameters were obtained through the CATMAN EASY software. The eigenfrequency of the first eigenmode, the damping factors per mass unit and per unit length, the loss factor and the dynamic Young modulus and stiffness have been also determined. Based on the experimental results, it can be concluded that the materials with epoxy resin reinforced with hemp have better vibration damping properties as compared to the composites made from epoxy reinforced with cotton fibers.
\end{abstract}

KEYWORDS: Hemp, Cotton, Epoxy resin, Dynamic Stiffness, Dynamic Young modulus.

\section{INTRODUCTION}

The variety of Gossypium hirsutum accounts for $87 \%$ of the world's production of cotton, other types of cotton being differentiated in this way: Gossypium barbadense 8\%, Gossypium herbaceum 3\% and Gossypium arboretum $2 \%[1,2]$. The cotton fibers have unicellular seed hairs of the cotton plant bolls. When it is mature, the cotton fruit bursts, revealing a bunch of fibers around $0.012 \ldots 0.045 \mathrm{~mm}$ in diameter, and between $25 \ldots 60 \mathrm{~mm}$ in length [1]. Cotton is of tropical origin, but it is also well cultivated in areas with temperate climates. The cotton fibers were used by early societies to produce textiles. Cotton fibers have a three walled structure. A first exterior wall protects the primary wall. The secondary wall is made of cellulose, and the third wall surrounds the lumen [1]. There are some already known mechanical properties regarding the cotton fibers. For example, [3] studied the thermal characteristics and several mechanical parameters, such as: impact strength, fracture toughness, flexural strength and flexural modulus for cotton fibers reinforced geopolymers containing up to $4.1 \mathrm{wt} \%$. The results showed that the enhancement of mechanical properties was achieved at a fiber content of $2.1 \mathrm{wt} \%$. The thermal analysis showed that fly-ash based geopolymer can prevent the degradation of cotton fabric at elevated temperatures. The usage of cotton fibers in geopolymers is also studied in [4]. Mechanical properties, such as flexural strength, flexural modulus, impact strength and fracture toughness of geopolymer composites reinforced with 3.6, 4.5, 6.2 and $8.3 \mathrm{wt} \%$ cotton fibres are studied. The results showed that all the mechanical properties of the composites are improved by increasing the cotton fibre contents. In [5], three different types of cotton fibers were studied. Those fibers had different physical properties, such as: maturity, fineness, micronaire, length, tenacity and so on. It was shown that the creep behaviour of cotton fibers can be assimilated to a Voigt model in series with a spring, and that the difference in the behaviour between the single fibers and bundles is related to inter-fiber friction. [6] examines the tensile properties of cotton fibers.

Hemp is native to Central Asia and has been cultivated for more than 12,000 years [7]. The hemp plants have an impressive growth rate and they rapidly cover the ground, thus suppressing some weeds and soil pathogens. Hemp also restores some soil nutrients. The plant has a very deep root and it is a beneficial 
break crop because it cleans the soil structure. Hemp can grow between 1200 ...5000 $\mathrm{mm}$ [8]. The elementary fibers have thick walls in polygonal cross-section. Those fibers also exhibit cracks, swellings and other irregularities on the surface. The hemp fibers are water and moth attack resistant and have good tensile mechanical properties. The hemp fibers have an increased tenacity ( $20 \%$ higher than flax fibers), but lower elongation at break as compared to flax fibers [1, 3]. The mechanical properties of hemp fibers are [1], [9], [10], [11]: Young modulus 2600 -90000 MPa, tensile strength 450-900 $\mathrm{MPa}$, elongation at break $1.6 \%$. In [11], for neat hemp fibers, the Young modulus is $21400 \mathrm{MPa}$, the tensile strength is $286 \mathrm{MPa}$ and the elongation at the breaking point is $2 \%$. For hemp fibers modified through bacterial cellulose, the Young modulus is $8800 \mathrm{MPa}$, the tensile strength is $171 \mathrm{MPa}$ and the elongation at the breaking point is $2.9 \%$ [11]. For modified hemp fibers with purification, a hypothesis which means the extraction of postbacterial cellulose modified fibers with $\mathrm{NaOH}$ at $80{ }^{\circ} \mathrm{C}$, the Young modulus is $8000 \mathrm{MPa}$, the tensile strength is $130 \mathrm{MPa}$ and the elongation at the breaking point is $2.9 \%$ [11]. Other studies regarding the static mechanical properties for composite materials with dammar/epoxy matrix reinforced with hemp and cotton fibers are presented in [12]. Several samples are made from these materials and they are tensile tested. The results obtained show the breaking strength of $66 \mathrm{MPa}$ for cotton and $75 \mathrm{MPa}$ for hemp; the static Young modulus $4134 \mathrm{MPa}$ for cotton and $6548 \mathrm{MPa}$ for hemp. From the studied engineering literature, the authors can see that little information is presented regarding the dynamic mechanical properties for composites reinforced with hemp and cotton. That is why, in this research, they built several green composites with natural reinforcement (cotton and hemp) and synthetic resin (epoxy resin). For these composites, the authors determined the dynamic mechanical properties.

\section{MATERIALS AND METHODS}

The authors designed several samples, having the following geometrical characteristics: length $=410$ $\mathrm{mm}$, width $=15 \mathrm{~mm}$ and thickness $=4 \mathrm{~mm}$ (for the samples with four layers of reinforcement), $6 \mathrm{~mm}$ (for the samples with five layers of reinforcement). The authors obtained the following mass values: mass $=40$ grams (for the samples with four layers of reinforcement), mass $=100$ grams (for the samples with five layers of reinforcement). Figure 1 shows several samples with $4 \mathrm{~mm}$ thickness and four layers of reinforcement respectively.

The authors used the 1050 Resoltech epoxy resin with its 1055 hardener as a matrix. The producer is presented in [13] and the epoxy resin was bought from [14]. The casting was performed at room temperature with a waiting window of 24 hours for polymerization. These parameters are recommended by the producer.

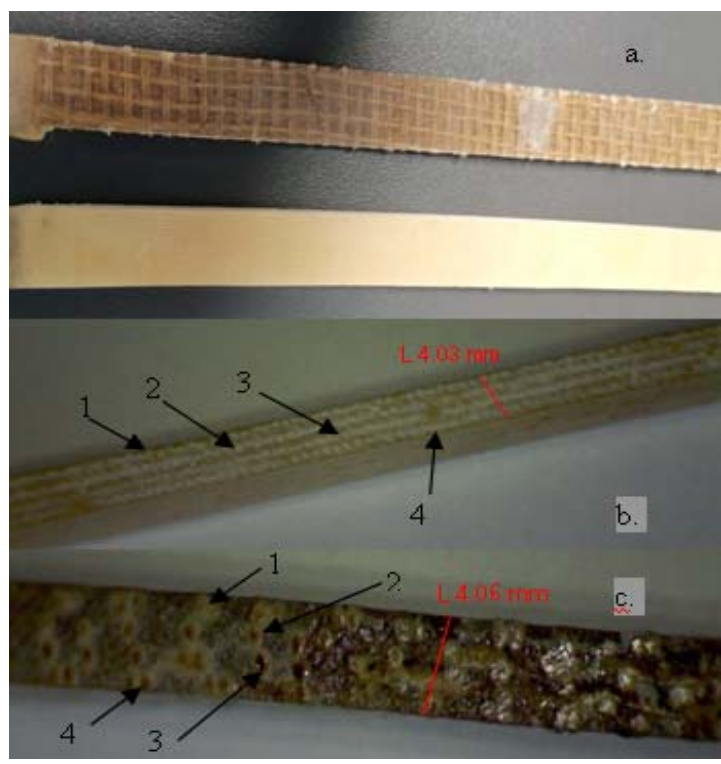

Fig. 1. a) Samples with $4 \mathrm{~mm}$ thickness and four layers of reinforcement (cotton and hemp); b) Thickness measurement and layers numbers for the cotton sample; c) Thickness measurement and layers numbers for the hemp sample

The specimens (strips) were clamped at one end and left free at the other end. At the free end, a B\&K 8309 accelerometer was placed in order to record the free vibrations. As in [5] and [6], several free length values were considered for the samples (values in mm): 270 , $290,310,330,350,370$. Those values were chosen in order to determine the Young modulus values and the dynamic stiffness for the samples considered (see table 1 presented in chapter 3 of this research). For a final value of the dynamic Young modulus and dynamic stiffness, the arithmetic mean can be calculated with the values determined for the $270,290,310,330,350$, $370 \mathrm{~mm}$ free lengths. The accelerometer was connected to a measuring system, which consists of: B\&K NEXUS 2692-A-0I4 signal conditioner and HBM SPIDER 8 data acquisition system. The SPIDER 8 apparatus was connected to a notebook through a USB port. A similar experimental setup was used before in [13] and [14], where good results for other composite sandwich platbands were obtained. The frequency range chosen for the experiment was between 0 ... $240 \mathrm{~Hz}$.

\section{RESULTS AND DISCUSSION}

The authors marked the samples as follows: sample 1 (sample with 4 layers of cotton), sample 2 (samples with 5 layers of cotton), sample 3 (samples with 4 layers of hemp) and sample 4 (samples with 5 layers of hemp). From the free vibrations recording, the damping factor per unit mass was determined as follows [15], [16]: 
- the values at which the displacement is zero were determined (meaning the points where the graph crosses the time axis);

- the period of movement cancellation was determined, more precisely, $T$ is the time interval double between two successive cancellations;

- the frequency $v=\frac{1}{T}$ and the pulsation $\omega=\frac{2 \pi}{T}$ were determined;

- $\quad$ the damping factor was determined by Eq. 1.

$$
\mu=0.5 \cdot c=(K T)^{-1} \ln \frac{B_{i}}{B_{i+j}},
$$

where $B_{i}$ and $B_{i+j}$ are maximums separated by $\mathrm{K}$ periods and $\mathrm{c}$ is the damping factor per length unit.

The free vibrations recording for sample 1 with $370 \mathrm{~mm}$ free length is shown in figure 2. The damping factor per mass unit calculus for sample 1, with the 370 $\mathrm{mm}$ free length and 5 cycles, is seen in Fig. 3 .

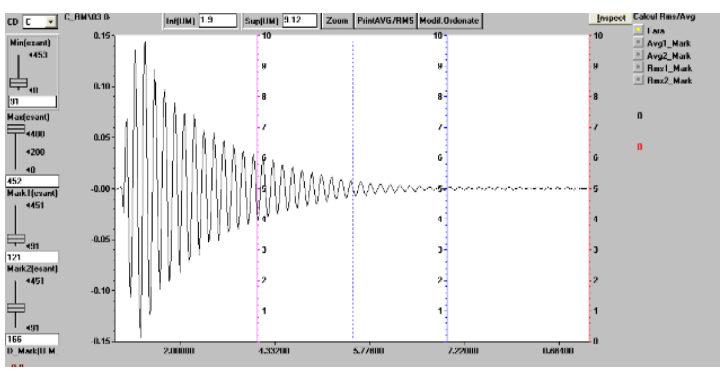

Fig. 2. Free vibrations recording for sample 1, free length $370 \mathrm{~mm}$

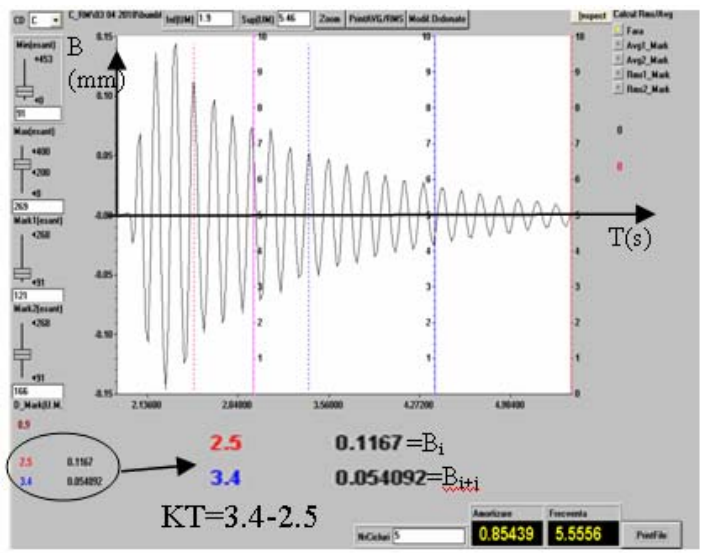

Fig. 3. The damping factor per unit mass and eigenfrequency determination for sample 1 , free length $370 \mathrm{~mm}$
The damping factor per length unit is determined by Eq.2 [6].

$$
C=2 \cdot \mu \cdot(\rho A),
$$

The loss factor can be determined by Eq. 3 [6].

$$
\eta=\mu \cdot\left(\pi \cdot v_{\xi}\right)^{-1}
$$

The equation 3 makes use of the following notations: $\zeta$ - critical damping; $\omega_{\xi}$ - eigen pulsation; $\mu$ damping factor per mass unit; $\eta$ - loss factor; $v_{\xi}$ - the eigen frequency; $t$ - time; $\xi$ is the number of the eigenmode. The dynamic stiffness EI and Young modulus $E$ can be determined by Eq.4 and Eq. 5 [6].

$$
\begin{aligned}
& \mathrm{EI}=\left(\frac{1}{\beta}\right)^{4} \cdot\left[v \cdot 2 \cdot \mu \cdot(\rho \mathrm{A})^{0.5}\right]^{2} \\
& \mathrm{EI}=\left(\frac{1}{\beta}\right)^{4} \cdot\left[v \cdot 2 \cdot \mu \cdot(\rho \mathrm{A})^{0.5} \cdot \mathrm{I}^{-0.5}\right]^{2}
\end{aligned}
$$

The mathematical relations (5) and (4) include the following notations: A - the transversal area, $\rho$ - the strips density, 1 the strips free length, I the moment of inertia, and $\mathrm{E}$ the Young modulus. All the dynamic results are included in Table 1. Figures 4 to 7 show the eigefrequency, damping factor per mass unit variations versus the strips free length.

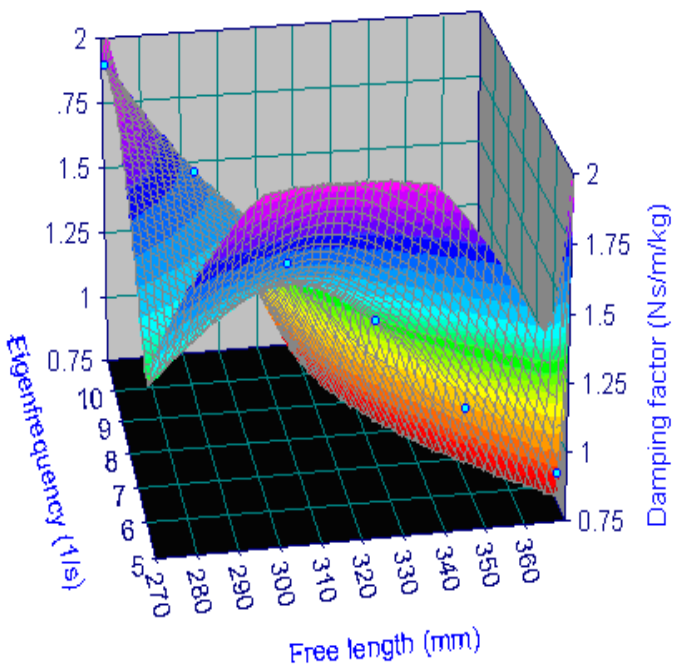

Fig. 4. The damping factor per mass unit and eigenfrequency variations versus the strips free length, for sample 1 
Table 1. Dynamic mechanical characteristics

\begin{tabular}{|c|c|c|c|c|}
\hline $\begin{array}{l}\text { Width } \\
\text { [mm] }\end{array}$ & $\begin{array}{c}\text { Specific mass } \\
{[\mathrm{kg} / \mathrm{m}]}\end{array}$ & $\begin{array}{c}\text { Free length } \\
{[\mathrm{mm}]}\end{array}$ & $\begin{array}{c}\text { Eigenfrequency } \\
{[1 / \mathrm{s}]}\end{array}$ & $\begin{array}{c}\text { Damping factor per } \\
\text { unit mass } \\
{[(\mathrm{Ns} / \mathrm{m}) / \mathrm{kg}]} \\
\end{array}$ \\
\hline 4 & 0.098 & 370 & 5.555 & 0.854 \\
\hline 4 & 0.098 & 350 & 6.425 & 1.011 \\
\hline 4 & 0.098 & 330 & 7.188 & 1.276 \\
\hline 4 & 0.098 & 310 & 7.883 & 1.433 \\
\hline 4 & 0.098 & 290 & 9.389 & 1.637 \\
\hline 4 & 0.098 & 270 & 10.709 & 1.926 \\
\hline 6 & 0.244 & 370 & 7.638 & 1.252 \\
\hline 6 & 0.244 & 350 & 8.372 & 1.324 \\
\hline 6 & 0.244 & 330 & 9.242 & 1.421 \\
\hline 6 & 0.244 & 310 & 10.562 & 1.565 \\
\hline 6 & 0.244 & 290 & 12.186 & 1.686 \\
\hline 6 & 0.244 & 270 & 13.848 & 1.806 \\
\hline 4 & 0.098 & 370 & 6.787 & 0.819 \\
\hline 4 & 0.098 & 350 & 8.166 & 1.180 \\
\hline 4 & 0.098 & 330 & 9.047 & 1.722 \\
\hline 4 & 0.098 & 310 & 10.132 & 2.215 \\
\hline 4 & 0.098 & 290 & 11.668 & 2.926 \\
\hline 4 & 0.098 & 270 & 12.900 & 3.961 \\
\hline 6 & 0.244 & 370 & 9.399 & 1.686 \\
\hline 6 & 0.244 & 350 & 10.660 & 1.866 \\
\hline 6 & 0.244 & 330 & 12.225 & 2.227 \\
\hline 6 & 0.244 & 310 & 13.796 & 2.681 \\
\hline 6 & 0.244 & 290 & 15.628 & 3.034 \\
\hline 6 & 0.244 & 270 & 17.780 & 3.593 \\
\hline $\begin{array}{c}\text { Sample } \\
\text { [mm] }\end{array}$ & $\begin{array}{c}\text { Damping factor } \\
\text { per length unit } \\
{\left[\mathrm{Ns} / \mathrm{m}^{2}\right]} \\
\end{array}$ & Loss factor & $\begin{array}{c}\text { Dynamic Young } \\
\text { modulus } \\
{[\mathrm{MPa}]} \\
\end{array}$ & $\begin{array}{c}\text { Dynamic stiffness } \\
{\left[\mathrm{Nm}^{2}\right]}\end{array}$ \\
\hline 1 & 0.167 & 0.049 & 2262 & 0.181 \\
\hline 1 & 0.198 & 0.05 & 2423 & 0.194 \\
\hline 1 & 0.25 & 0.057 & 2397 & 0.192 \\
\hline 1 & 0.281 & 0.058 & 2245 & 0.18 \\
\hline 1 & 0.321 & 0.055 & 2439 & 0.195 \\
\hline 1 & 0.304 & 0.047 & 2396 & 0.192 \\
\hline 2 & 0.611 & 0.052 & 3155 & 0.852 \\
\hline 2 & 0.646 & 0.05 & 3035 & 0.82 \\
\hline 2 & 0.693 & 0.049 & 2923 & 0.789 \\
\hline 2 & 0.764 & 0.047 & 2973 & 0.803 \\
\hline 2 & 0.823 & 0.044 & 3031 & 0.819 \\
\hline 2 & 0.881 & 0.042 & 2941 & 0.794 \\
\hline 3 & 0.161 & 0.038 & 3377 & 0.27 \\
\hline 3 & 0.231 & 0.046 & 3914 & 0.313 \\
\hline 3 & 0.338 & 0.061 & 3797 & 0.304 \\
\hline 3 & 0.434 & 0.07 & 3709 & 0.297 \\
\hline 3 & 0.573 & 0.08 & 3767 & 0.301 \\
\hline 3 & 0.776 & 0.098 & 3460 & 0.277 \\
\hline 4 & 0.823 & 0.057 & 4778 & 1.29 \\
\hline 4 & 0.911 & 0.056 & 4921 & 1.329 \\
\hline 4 & 1.087 & 0.058 & 5115 & 1.381 \\
\hline 4 & 1.308 & 0.062 & 5073 & 1.37 \\
\hline 4 & 1.481 & 0.062 & 4985 & 1.346 \\
\hline 4 & 1.753 & 0.064 & 4848 & 1.309 \\
\hline
\end{tabular}




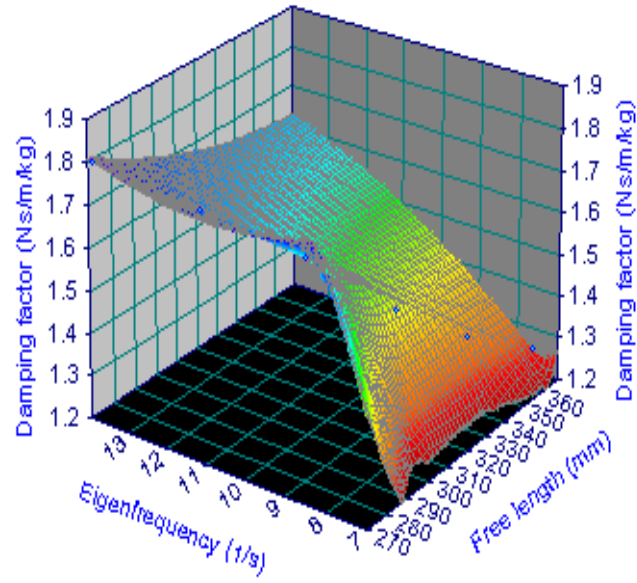

Fig. 5. The damping factor per mass unit and eigenfrequency variations versus the strips free length, for sample 2

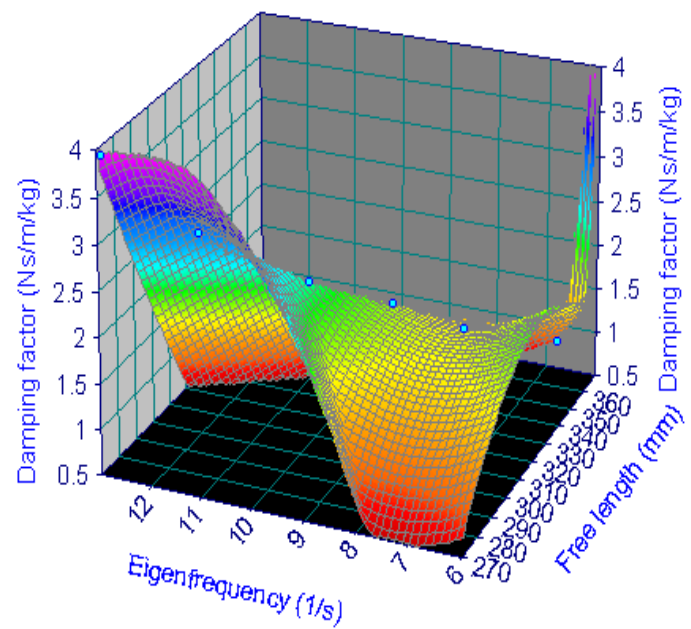

Fig. 6. The damping factor per mass unit and eigenfrequency variations versus the strips free length, for sample 3

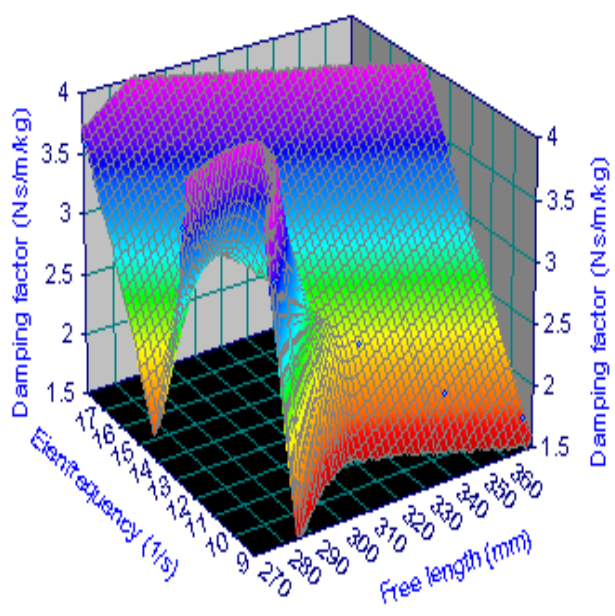

Fig. 7. The damping factor per mass unit and eigenfrequency variations versus the strips free length, for sample 4
The damping factors analysis shows that these factors must be experimentally determined for each type of material and sample, being difficult to deduce a quantitative correspondence with the parameters influencing the damping, either directly or indirectly.

The values of the damping factors may depend on several features such as: sample dimensions, specific mass or quantity of material in the sample, the elastic and damping properties of the component materials. The sample width can influence the damping coefficient, by determining the surface on which the air friction acts on the sample.

In addition to these general conclusions, by studying Table 1 and Figures 4, 5, 6, 7 and 8, the authors can add new particular ones:

- the damping factor per mass unit and length unit decreases with the bar thickness (meaning that those parameters have higher values for the $6 \mathrm{~mm}$ thick samples as compared to the $4 \mathrm{~mm}$ thick samples);

- $\quad$ the damping factor per mass unit or per length unit decrease exponentially with the free length of the strip;

- $\quad$ the eigenfrequency increases as the bars thickness increases;

- the loss factor, for the hemp reinforced samples, increases as the bars free length decrease;

- the samples reinforced with hemp fibers have an increased loss factor as compared to the samples reinforced with cotton;

- $\quad$ the samples reinforced with hemp have increased dynamic mechanical properties (dynamic stiffness and Young modulus), when compared to the samples reinforced with cotton; this result can be explained by the fact that the hemp fibers have superior mechanical properties when compared to the cotton ones.

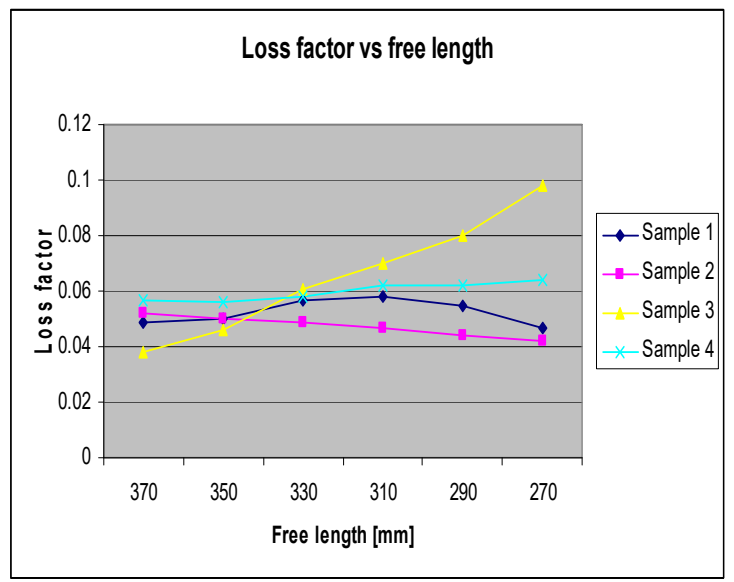

Fig. 8. The loss factor versus samples free length

The dynamic Young modulus obtained from this paper is different than the static one which can be obtained from a simple tensile test on a universal 
loading machine. For composite samples, the dynamic Young modulus is usually (but not always) higher than the static one. An explanation of the increased value of the dynamic Young modulus can appear if there is not enough time during the application of the force for the strain to occur, and thus the overall strain appears smaller and the modulus from the dynamic method becomes higher than the one from the static one. Also, the strain from the static method is of macro proportions and in the vibration technique the atoms are barely displaced from their equilibrium sites. The first derivative of the applied force with respect to atomic displacement decreases as the atoms of the lattice are separated. So, the Young modulus for the static method is lower than the dynamic one, because the atom displacement is larger [17].

In a future study, a finite element analysis like the one from [18] will be carried out by studying the joining of some thick elements made from composite materials reinforced with cotton or hemp fibers.

\section{CONCLUSIONS}

Due to their dynamic mechanical properties (vibration damping, dynamic Young modulus, dynamic stiffness, loss factor), these types of composites may be used for:

- plane floor building;

- door frames;

- roofing sheets;

- $\quad$ ships floor building;

- walls of civil constructions;

- reusable devices used to immobilize fractures (making one-size-fits-all pieces that can be fixed afterwards by a self-adhesive bandage systems);

- making almost-environment-friendly parquet floors (in order to replace wood or PVC);

- concrete forming;

- strengthening thin reinforced concrete slabs.

On the basis of the results obtained it can be concluded that the materials with epoxy resin reinforced with hemp have better vibration damping properties and increased dynamic mechanical properties as compared to the composites made from epoxy reinforced with cotton fibers.

The original experimental results obtained in this paper are related to the dynamic behaviour of the samples reinforced with hemp and cotton.

\section{REFERENCES}

[1] Mohanty, A., Misra, M., Drzal, L., Natural Fibers, Biopolymers and Biocomposites, Taylor \& Francis Group, New York, 2005.

[2] Fosler, Th., Nachwachsende Rohstoffe in technischen Anwendungsn am Beispiel Fasern/Vliese, Textilveredlung, vol. 30, no.2, 1995

[3] Alomayri, T., Shaikh,F.U.A., Low, I., M., Thermal and mechanical properties of cotton fabric reinforced geopolymer composites, J Mater Sci, vol. 48, 2013, pp. 6746-6752.

[4] Alomayri, T., Shaikh,F.U.A., Low, I., M., Synthesis and mechanical properties of cotton fabric reinforced geopolymer composites, Composites Part B: Engineering, vol. 60, 2014, pp. 3642.

[5] Mahjoub, W., Harzallah, O., Gourlot, J., P., Drean, J., Y., Single and bundle cotton fiber testing; Friction component, $18^{\text {th }}$ AUTEX World Textile Conference, 20-22 June, Istanbul, Turkey, 2018.

[6] Mahjoub, W., Harzallah, O., Drean, J., Y., Cotton fiber tensile properties, Cotton Fibres: Characteristics, Uses and Performance, 1st ed. Nova Science Publisher, 2017.

[7] Katalyse-Institut für angewandte Umweltforschung (Hrsg.), Hanf \& Co. Die Renaissance der heimischen Faserpflanzen, Verlag Die Werkstatt, Göttingen, 1995

[8] Mediavilla, V., Bassetti, P., Leupin, M., Mosimann, E., Agronomische Eigenschaften von Hanfsorten, Agarforschung, vol. 393, no. 6, 1999

[9] Pilla, S., Handbook of Bioplastics and Biocomposites Engineering Applications. Chapter 1, New Jersey: John Wiley \& Sons, 2011, pp. 1-14.

[10] Hu, N., et. al., Composites and their applications, Rijeka: InTech Publishing, 2012

[11] Hodzic, A., Shanks, R., Natural fibre composites. Materials, processes and properties, Philadelphia: Woodhead Publishing Limited, 2014.

[12] Stănescu, M., M., A study regarding the mechanical behaviour of Dammar based composite materials, reinforced with natural fiber fabrics, Materiale Plastice, vol.52, no.4, 2015, pp. 596-600.

[13] https://www.resoltech.com/en/markets/1050-detail.html

[14] http://www.polydis.ro/wp-content/uploads/2014/08/Resoltech1050.pdf

[15] Mirițoiu, C.M., Bolcu, D., Stănescu, M.M., Ciucă, I., Cormos, R., Determination of Damping Coefficients for Sandwich Bars with Polypropylene Honeycomb Core and the Exterior Layers Reinforced with Metal Fabric, Materiale Plastice, 49, 2012, pp. 118 123

[16] Mirițoiu, C.M., Burada, C.O., Stănescu, M. M., Bolcu, A. Dynamic and static behaviour of composite sandwich platbands with kevlar honeycomb core, Romanian Journal of Materials, 2018, vol 48, no. 1, pp. 101-107.

[17] Miriţoiu, C.M., Stănescu, M. M., Bolcu, D., Researches regarding the mechanical properties of a new hybrid vegetal resin, Materiale Plastice, 2020, Vol. 57, no. 1, pp. 37-45.

[18] Bîrsan, D., Toma, C., Scutelnicu, E., Comparative simulation by finite element analysis of conventional and tandem submerged arc welding, Annals of "Dunarea de Jos" University, Fascicle XII, Welding Equipment and Technology, 2016, Vol. 27, pp. 21-28. 